\title{
Designing Scaffolds to Enhance Transplanted Myoblast Survival and Migration
}

\author{
ELLIOTT HILL, Ph.D., ${ }^{1}$ TANYARUT BOONTHEEKUL, M.S., ${ }^{2,3}$ and DAVID J. MOONEY, Ph.D. ${ }^{3}$
}

\begin{abstract}
Myoblast transplantation is currently limited by poor survival and integration of these cells into host musculature. Transplantation systems that enhance the viability of the cells and induce their outward migration to populate injured muscle may enhance the success of this approach to muscle regeneration. In this study, enriched populations of primary myoblasts were seeded onto delivery vehicles formed from alginate, and the role of vehicle design and local growth factor delivery in cell survival and migration were examined. Only $5 \pm 2.5 \%$ of cells seeded into nanoporous alginate gels survived for $24 \mathrm{~h}$ and only $4 \pm 0.5 \%$ migrated out of the gels. Coupling cell adhesion peptides $\left(G_{4}\right.$ RGDSP) to the alginate prior to gelling slightly increased the viability of cells within the scaffold to $16 \pm 1.4 \%$ and outward migration to $6 \pm 1 \%$. However, processing peptide-modified alginate gels to yield macroporous scaffolds, in combination with sustained delivery of HGF and FGF2 from the material, dramatically increased the viability of seeded cells over a 5-day time course and increased outward migration to $110 \pm 12 \%$. This data indicate long-term survival and migration of myoblasts placed within polymeric delivery vehicles can be greatly increased by appropriate scaffold composition, architecture, and growth factor delivery. This system may be particularly useful in the regeneration of muscle tissue and be broadly useful in the regeneration of other tissues as well.
\end{abstract}

\section{INTRODUCTION}

$\mathbf{T}$ He total cost of Musculoskeletal disease in the United States in 2000 has been estimated at \$254 billion and, in developing countries, the figure is estimated at $\$ 100$ billion. $^{1}$ If the increasing demand for the replacement of muscle mass lost as a result of trauma or reconstructive surgery is added to this economic impact, it is apparent that the need for new and more effective methods to generate and regenerate lost muscle tissue is enormous. Under normal conditions, muscles can repair themselves by regenerating damaged muscle fibers and restoring muscle strength. Following an initial necrosis of damaged muscle fibers, an inflammatory response is initiated $^{2-4}$ that activates a resident population of quies- cent cells termed satellite cells. ${ }^{2-8}$ These myogenic cells proliferate, migrate to the site of injury, differentiate and fuse to form mature myofibers, or fuse with existing myofibers, thus regenerating damaged muscle fibers and restoring their function. ${ }^{9}, 10$ When these normal processes are compromised by disease or age, damaged muscle fibers are instead replaced by infiltrating fibrous tissue or fat, leading to a net loss of muscle mass and a resultant loss of strength. ${ }^{11}$

Environmental cues work in concert with transcription factors to activate satellite cells, induce them to proliferate, and eventually differentiate into mature muscle fibers. ${ }^{12,13}$ Numerous trophic factors have been implicated in in vitro studies as initiators of satellite cell activation. Of these candidate trophic factors, both hepato-

\footnotetext{
${ }^{1}$ Department of Biologic and Material Sciences, ${ }^{2}$ Department of Chemical Engineering, University of Michigan, Ann Arbor, Michigan.

${ }^{3}$ Division of Engineering and Applied Sciences, Harvard University, Cambridge, Massachusetts.
} 
cyte growth factor (HGF) and members of the fibroblast growth factor (FGF) family have been demonstrated to have a physiological role in skeletal muscle regeneration. ${ }^{14,15}$ Both types of factors initiate satellite cell activation, ${ }^{16}$ stimulate satellite cells to enter the cell cycle in vivo, ${ }^{7}$ and are potent mitogens for satellite cells. ${ }^{17}$ In addition, the receptor for HGF, c-met, is expressed in both quiescent and activated satellite cells, ${ }^{18}$ and FGF-2 is present in the basement membrane surrounding developing myotubes. ${ }^{19}$ Both HGF and FGF-2 are heparin-binding proteins that depend on heparan sulfate proteoglycans (HSPG) to facilitate receptor activation. ${ }^{20}$ While HSPGs are ubiquitous on the surface of the cells of mammals, a specific family of HSPGs called Syndecans have been found to play a role in FGF-2 signaling. In addition, Syndecans 3 and 4 have been documented on both quiescent and activated satellite cells. ${ }^{19}$ Taken together, these studies suggest that HGF and FGF-2 may play important physiological roles in regulating satellite cell activation.

There are three distinct approaches currently being investigated to therapeutically intervene in the muscle regenerative process. First, cells in the tissues can be stimulated to re-enter the cell cycle and repopulate lost or damaged tissues by the injection of growth factors into the site of interest. ${ }^{7}$ The second approach is based on the current interest in gene therapy and targets the intrinsic cell proliferation and differentiation program of muscle forming cells. ${ }^{21,22}$ The third approach is based on the delivery of exogenous cells, expanded in culture, to repair the defect and restore function to the tissue. ${ }^{23}$ Current strategies in this third approach include direct injection of cells into the injury site, the utilization of a carrier to provide an artificial matrix for cell delivery, or a combination of cell, matrix, and growth factor delivery to increase regeneration. ${ }^{24-26}$ Cell transplantation approaches have focused on satellite cells ${ }^{27-29}$ and are gaining growing interest as a potential treatment alternative for patients with musculodegenerative diseases such as muscular dystrophy and for chronic or congenital cardiomyopathies. However, while animal studies were initially promising, attempts to transplant human satellite cells have been disappointing. Transplanted myogenic cells undergo rapid and massive necrosis, resulting in less than $5 \%$ of transplanted cells incorporating into the host myofibers after 48 hours. $^{30,31}$

We propose a new approach to myoblast transplantation-delivery on a material that maintains the viability of the cells for extended time periods while simultaneously encouraging outward migration of the cells to populate surrounding host muscle fibers. Biodegradable polymer matrices that co-deliver satellite cells and inductive molecules that signal endogenous cells to participate in muscle regeneration may be specifically useful in this approach. The role of coupling cell adhesion ligands to the matrix, material pore structure, and growth factor deliv- ery from the material were studied in vitro in these studies. Alginate, the hydrophilic, biocompatible polysaccharide derived from seaweed, has carboxylic acid functional groups that offer the potential for covalent modification with cell adhesion peptides, allowing for the controlled presentation of signals that induce tissue development. ${ }^{32-34}$ In addition, controlling the molecular weight distribution of the polymer used to form gels allows one to regulate gel degradation ${ }^{35}$ and to increase the viability of alginateencapsulated cells. ${ }^{36}$ Taken together, these properties make alginate hydrogels a useful model material for these studies. Finally, in addition to primary myoblasts, a myoblast cell line ( $\mathrm{C} 2 \mathrm{C} 12$ cells) that produces characteristic muscle proteins was used as a model system in proof of principle experiments and as positive controls for the analysis of the expression of myogenic proteins.

\section{MATERIALS AND METHODS}

\section{Alginate modification}

Low-molecular-weight $\left(\mathrm{Mw}=5.3 \times 10^{4} \mathrm{~g} / \mathrm{mol}\right)$ modified alginate was produced by irradiating ultra-pure MVG alginate powder (Pronova, Oslo, Norway) with a cobalt-60 source for $4 \mathrm{~h}$ at a $\gamma$-dose of 5.0 Mrad (Phoenix Lab, University of Michigan, Ann Arbor, MI), as previously specified. ${ }^{32,36}$ High-molecular-weight $(\mathrm{Mw}=$ $\left.2.7 \times 10^{5} \mathrm{~g} / \mathrm{mol}\right)$ ultra-pure alginate (MVG, Pronova) was also used to fabricate scaffolds. Both alginates were modified with covalently conjugated oligopeptides with a sequence of $\mathrm{G}_{4}$ RGDSP (Commonwealth Biotechnology, Richmond, VA ) at an average density of $3.4 \mathrm{mM}$ peptide/mole of alginate monomer using carbodiimide chemistry as previously described. ${ }^{34,37}$ Briefly, $2 \%$ irradiated alginate solutions were frozen and lyophilized until completely dry. Lyophilized alginate was added to MES buffer (Sigma-Aldrich, St. Louis, MO) to yield a $1 \%$ w/v solution, and EDC, Sulfo-NHS, and RGDSP peptide were added to the dissolved alginate and allowed to react for $20 \mathrm{~h}$. The reaction was quenched with hydroxylamine, and the solution was dialyzed with decreasing concentrations of $\mathrm{NaCl}(7.5,6.25,5.0,3.75,2.5,1.25$, and $0 \%$ ) over 3 days. The solution was purified via the addition of activated charcoal and subsequent sterile filtration. Sterile filtered alginate was frozen and lyophilized and stored at $-20^{\circ} \mathrm{C}$. Finally, the modified alginates were reconstituted in calcium-free DMEM (Invitrogen, Carlsbad, CA) to obtain $2 \% \mathrm{w} / \mathrm{v}$ solution $(50 \% \mathrm{LMW} /$ $50 \% \mathrm{MVG}$ used in all experiments) prior to gelation. Reconstituted alginate was stored at $4{ }^{\circ} \mathrm{C}$.

\section{Scaffold fabrication}

Three physical forms of scaffolds were prepared: nanoporous, microporous, and macroporous. To fabricate 
nanoporous alginate scaffolds, $5 \mathrm{~mL}$ non-modified or peptide-modified alginate containing myoblasts $\left(10^{6}\right.$ cell $\left./ \mathrm{mL}\right)$ was crosslinked by adding $200 \mu \mathrm{L}$ of $\mathrm{CaSO}_{4}(0.41 \mathrm{~g}$ $\mathrm{CaSO}_{4} / \mathrm{mL}_{\mathrm{dd}} \mathrm{H}_{2} \mathrm{O}$ ) (Sigma-Aldrich), and the resulting solution was expressed into molds $(2 \times 2 \times 5 \mathrm{~mm})$ constructed from polyvinylsulfoxane (PVS, Kerr, Orange, CA). The alginate was allowed to completely gel and placed at $37^{\circ} \mathrm{C}$ in high-glucose DMEM. To form microporous (10-20 $\mu \mathrm{m}$ pores) scaffolds, alginate was gelled in the absence of cells and then frozen at $-120^{\circ} \mathrm{C}$. The frozen scaffolds were lyophilized and stored at $-4^{\circ} \mathrm{C}$ until seeded with cells. To fabricate macroporous alginate scaffolds (400-500 $\mu \mathrm{m}$ diameter aligned pores), the peptide-modified alginate/calcium sulfate solution was expressed into the PVS mold containing wire porogens (RMO othodontic wire, Denver, CO). A sterile glass plate was placed over the mold containing the alginate and left undisturbed for $30 \mathrm{~min}$. After the alginate had completely gelled (30 $\mathrm{min})$, the alginate containing the wire porogens was frozen at $-70^{\circ} \mathrm{C}$. The frozen alginate gels were lyophilized overnight, wire porogens were carefully removed, and the dried scaffolds were stored at $-20^{\circ} \mathrm{C}$ until seeded with cells.

\section{Myoblast cultures}

Myoblasts were derived from 4-week-old C57BL/6 mice hindlimb skeletal musculature. Under sterile conditions, the tibialis muscle of the hindlimb was surgically excised, finely minced, and disassociated in $0.02 \%$ Trypsin (Gibco/Invitrogen) and 2\% collagenase type 4 (Worthington Biochemical, Lakewood, NJ) for $60 \mathrm{~min}$ at $37^{\circ} \mathrm{C} / 5 \% \mathrm{CO}_{2}$ while agitating on an orbital shaker. Disassociated cells were strained through a $70 \mu \mathrm{m}$ sieve, centrifuged at $1600 \mathrm{rpm}$ for $5 \mathrm{~min}$, and re-suspended in high-glucose DMEM, with added pyruvate (Gibco). The medium was further supplemented with $10 \%$ fetal bovine serum (FBS) and 10\% penicillin/streptomycin (P/S, Gibco) and this was used in all cell culture studies. Cells were plated and cultured at $37^{\circ} \mathrm{C} / 5 \% \mathrm{CO}_{2}$ for $72 \mathrm{~h}$ before media change. After $72 \mathrm{~h}$ in culture, the media were changed every $48 \mathrm{~h}$ until cells were $80 \%$ confluent (about 7 days). Cells were collected via centrifugation and overlaid on a Percoll gradient (Amersham Biosciences, Uppsala, Sweden) in a $15 \mathrm{~mL}$ Falcon tube. The gradient consisted of $3 \mathrm{~mL}$ of $20 \%$ Percoll diluted in PBS (Gibco), $3 \mathrm{~mL}$ of $30 \%$ Percoll diluted in DMEM (Invitrogen), and $3 \mathrm{~mL}$ of $35 \%$ Percoll diluted in Hamm's F-12 (Gibco). Cells were immediately centrifuged at $1600 \mathrm{rpm}$ for 20 min at $25^{\circ} \mathrm{C}$. The cells from the $30 \%$ fraction were collected and re-suspended in high-glucose DMEM.

\section{Immunohistochemistry}

To characterize myoblast cultures for the expression of myogenic proteins, Percoll purified primary myoblasts were plated on sterile cover slips overnight and fixed in
$0.2 \%$ paraformaldehyde for $20 \mathrm{~min}$. Cover slips were rinsed in phosphate-buffered saline with $0.5 \%$ Triton-X (PBS-X) and incubated in Hoechst nuclear dye (1:1000). Cover slips were also incubated in an anti-desmin (1/100) monoclonal antibody (Chemicon, Temecula, CA) followed by immunofluorescent secondary antibody (1:1000) (FITC, Jackson Labs, West Grove, PA). After secondary antibody binding, cover slips were mounted on glass slides with aqueous mounting medium and sealed with clear nail polish. Slides were viewed with a conventional fluorescent light microscope (Nikon Eclipse E-800, Tokyo, Japan) or stored in total darkness for later analysis. Images were captured utilizing NIH imaging software (Bethesda, MD), Spot digital camera (Sterling Heights, MI), and Adobe Photoshop (San Jose, CA).

\section{Western blot}

Total cytoplasmic protein was collected by finely mincing modified alginate scaffolds containing primary myoblasts and placing the resultant solutions in $1.5 \mathrm{~mL}$ Ep-

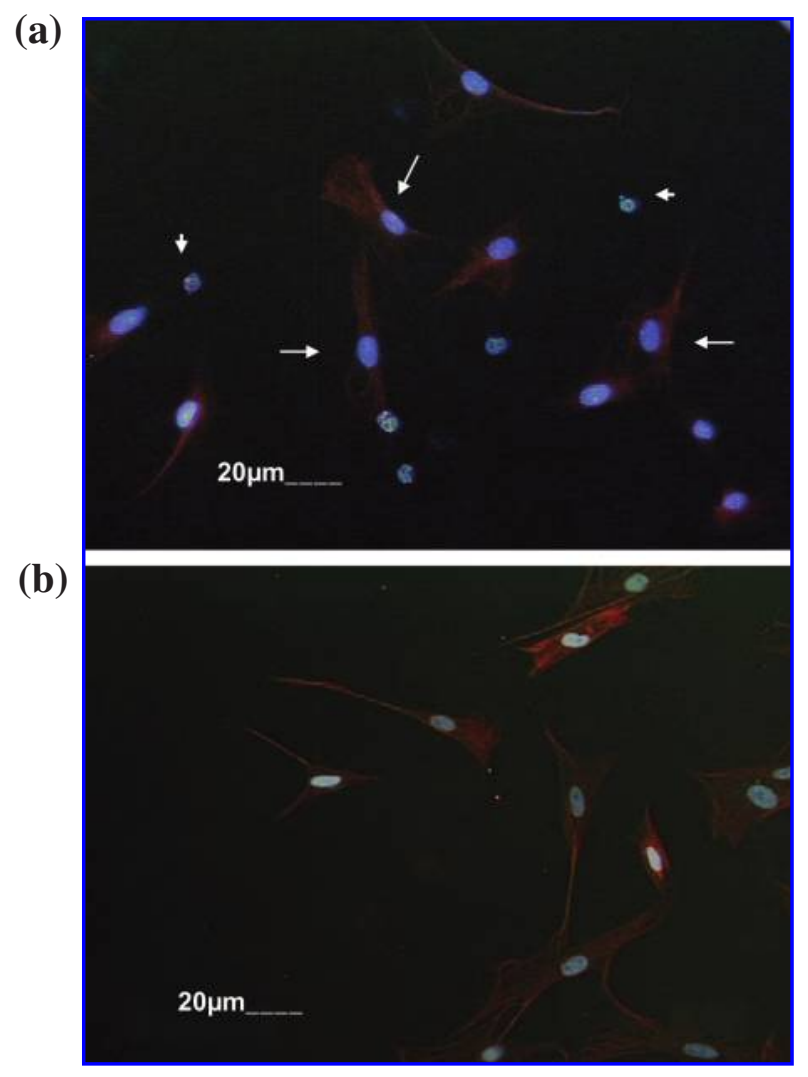

FIG. 1. Purity of primary skeletal muscle myoblast cultures is increased by Percoll fractionation. (a) Initial isolation resulted in heterogeneous cell population with myogenic cells (arrows) staining for both desmin and Hoescht nuclear stain. In contrast, nonmyogenic cells are only stained with the nuclear dye (arrowheads). (b) Percoll fractionation resulted in homogeneous myogenic cultures. (Color images are available online at www.liebertonline.com/ten). 
pendorf tubes. Fifty $\mu \mathrm{L}$ of passive lysis buffer (Promega, Madison, WI) were added directly to the minced scaffold and incubated at $37^{\circ} \mathrm{C}$ for $10 \mathrm{~min}$. The amount of protein in each sample was quantified by dilution of $1 \mu \mathrm{m}$ of sample in $200 \mu \mathrm{m}$ protein assay reagent (BioRad, Hercules, CA), and the absorbance was measured at $595 \mathrm{~nm}$ with a Sunrise spectrometer (Durham, NC).

All samples were denatured using standard SDS page protocols, loaded at $25 \mu \mathrm{g}$ total protein per well in $8 \%$ Tris glycine polyacrylimide gels (Ready Gels, BioRad), and electrophoresed at 100 volts for $120 \mathrm{~min}$. After electrophoresis, proteins were transferred to PDVF membranes (BioRad) at 100 volts for $1 \mathrm{~h}$ utilizing the BioRad mini-blot. PDVF membranes were blocked in $1 \%$ bovine serum albumin (BSA) in Tris buffered saline with $0.1 \%$ Tween-20 (TBS-T) overnight at $4^{\circ} \mathrm{C}$. After blocking, PDVF membranes were incubated in the appropriate primary monoclonal antibody, either for desmin (1/100), myogenin (1/100), or MyoD (1/100) (all from Santa Cruz Biotechnology, Santa Cruz, CA), for $1 \mathrm{~h}$ at room temperature. Membranes were subsequently rinsed for 30 min in TBS-T $(15 \mathrm{~min} \times 2)$ and incubated in horseradish peroxidase conjugated goat anti-mouse secondary an- (a)

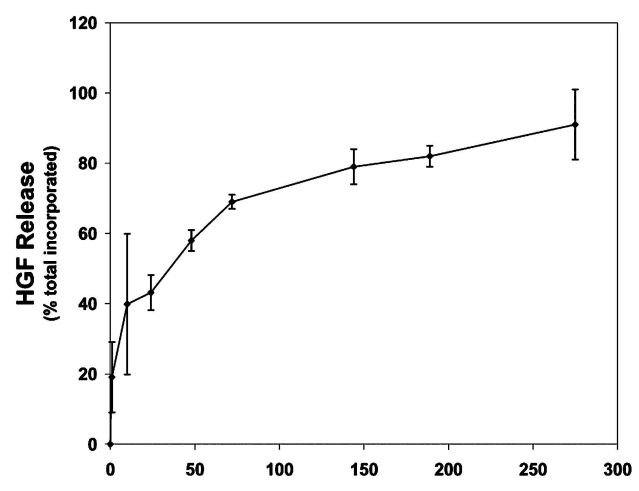

(c)

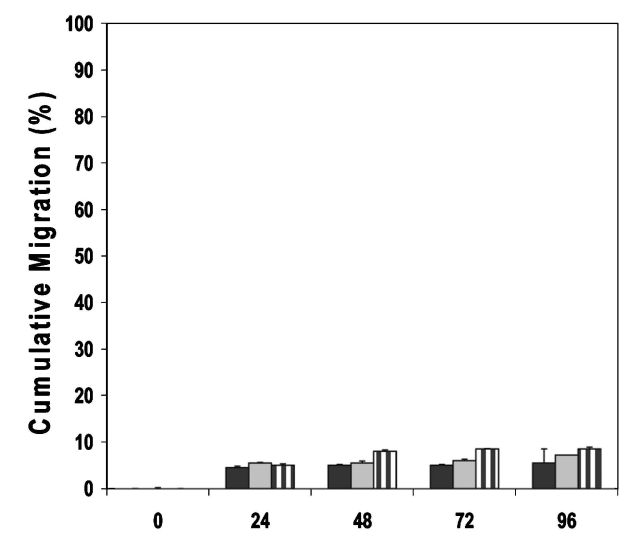

Time (hrs) tibody (1:1000 in TBS-T, BioRad) for $1 \mathrm{~h}$. Membranes were rinsed in TBS-T for $30 \mathrm{~min}(15 \mathrm{~min} \times 2)$, and proteins were detected via chemiluminescent detection kit (ECL, Amersham) and visualized by exposure to Hyperfilm ECL (Amersham).

\section{Growth factor incorporation and release kinetics}

To determine the release kinetics of HGF incorporated into modified binary alginate scaffolds, a quantitative sandwich enzyme immunoassay technique (ELISA) was employed. Recombinant HGF protein (Santa Cruz Biotechnology) was incorporated into alginate solutions prior to gelling $(500 \mathrm{ng} / \mathrm{mL})$, and gels were cast as previously described. After the gels had completely polymerized, they were cut into $5 \mathrm{~mm}$ squares and placed in 24 well plates, and $1 \mathrm{~mL}$ of PBS was added to each well. At various time points, the PBS was removed and stored at $4^{\circ} \mathrm{C}$ and fresh PBS was added to the scaffolds. The PBS samples were measured for total HGF content via quantitative ELISA (Quantikine, Minneapolis, MN), and the results were compared to the initially incorporated HGF. To determine the incorporation efficiency and re-

(b)

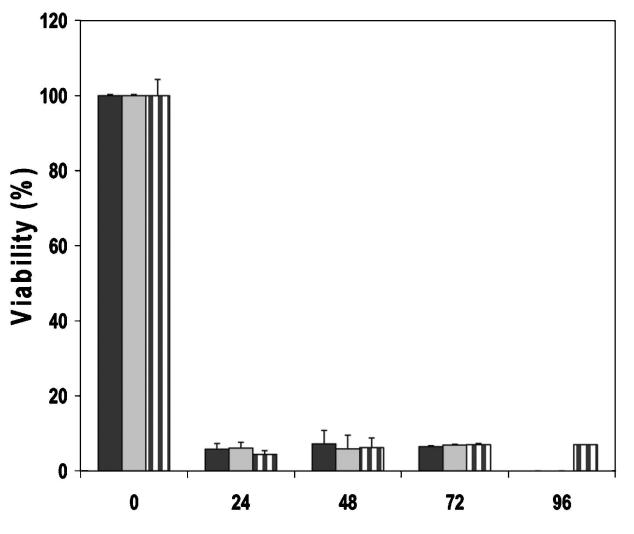

Time (hrs)
FIG. 2. HGF release from macroporous, non-peptidemodified alginate scaffolds (a). Values represent mean and standard deviation $(n=5)$. Viability (b) and cumulative migration (c) of primary myoblasts in and from, respectively, nanoporous scaffolds (black bar), nanoporous scaffolds releasing HGF (gray bar), and microporous scaffolds releasing HGF (striped bar). Values represent mean and $\operatorname{SD}(n=6)$. 
lease kinetics of FGF-2, $5 \mu \mathrm{ci}$ of $\mathrm{I}^{125}$-Bolton Hunter (PerkinElmer, Boston, MA) labeled FGF-2 was incorporated into $2.5 \mathrm{~mL}$ of the alginate solution prior to gelling. After gelling, gels were cut into squares $(2 \times$ $10 \times 10 \mathrm{~mm})$. Approximately $1 \mu \mathrm{ci}$ of labeled FGF-2 was incorporated into each scaffold. Alginate scaffolds were placed in separate polypropylene tubes containing $3 \mathrm{~mL}$ of $\mathrm{PBS}$ and incubated at $37^{\circ} \mathrm{C}$. At various time points the PBS was removed from the tubes, and fresh PBS was added to the scaffolds. The release of FGF-2 from the scaffolds was determined by measuring the radioactivity present in the PBS removed from the scaffolds with a gamma counter (Beckman, Fullerton, CA) and comparing the result to the initial total $\mathrm{I}^{125}$ FGF-2 incorporated into the sample.

\section{Migration and viability}

To determine the viability of primary myoblasts seeded in alginate scaffolds and to measure their ability to migrate out of the scaffolds, purified primary myoblasts were seeded in three-dimensional alginate scaffolds $(2 \times$ $10^{6}$ cell $/ \mathrm{mL}$ ) in 24 well plates. A solution of cells in medium $(50 \mu \mathrm{L})$ was pipetted into each lyophilized scaffold; the medium was rapidly absorbed. The resulting viability and migration of myoblasts from alginate scaffolds with both HGF and FGF-2 (250 ng/scaffold) incorporation was subsequently measured by maintaining scaffolds in culture for various time points. To analyze the viability of cells within the scaffolds, the scaffolds were finely minced and treated with $50 \mu \mathrm{L}$ of trypsin and $50 \mu \mathrm{L}$ of $5 \mathrm{mM}$ EDTA for $5 \mathrm{~min}$. Twenty $\mu \mathrm{L}$ of dissolved alginate and suspended cells were then added to $20 \mu \mathrm{L}$ of 4\% Trypan Blue solution (Sigma-Aldrich). The percent of viable cells was determined via Trypan Blue exclusion (dead cells appear blue due to their inability to exclude Trypan Blue from their nucleus), as viewed on a hemocytometer under standard microscopic conditions (Nikon Eclipse E800, 20×).

To measure migration of myoblasts from the scaffolds, scaffolds were placed in new 24 well plates at various time points, and the cells that had colonized the 24 well plates over the previous $24 \mathrm{~h}$ were removed via trypsinization and counted in a Coulter counter (Beckman). The total number of cells that migrated out of the scaffold was normalized to the total number of cells initially seeded into the alginate scaffolds. Cells from separate isolations were used to generate each data set, and duplication of experiments with cells from a second, independent isolation was performed to confirm results.

\section{SEM scaffold characterization}

The size and orientation of pores in alginate scaffolds were imaged utilizing a scanning electron microscope (ISIDS 130, Topcon Techn. CA, Tokyo, Japan). All samples were dried and sputter coated (Desk II, Denton Vacuum, Moorestown, NJ) prior to analysis.

\section{Statistical analysis}

All statistical analysis was done using student's $t$ test (two-tail comparisons) and SPSS software. Differences between conditions were considered significant if $p<0.05$.

\section{RESULTS}

\section{Characterization of myoblasts isolated from murine hindlimb}

Primary cells isolated from skeletal muscle were plated on cover slips and analyzed by staining with a Hoescht

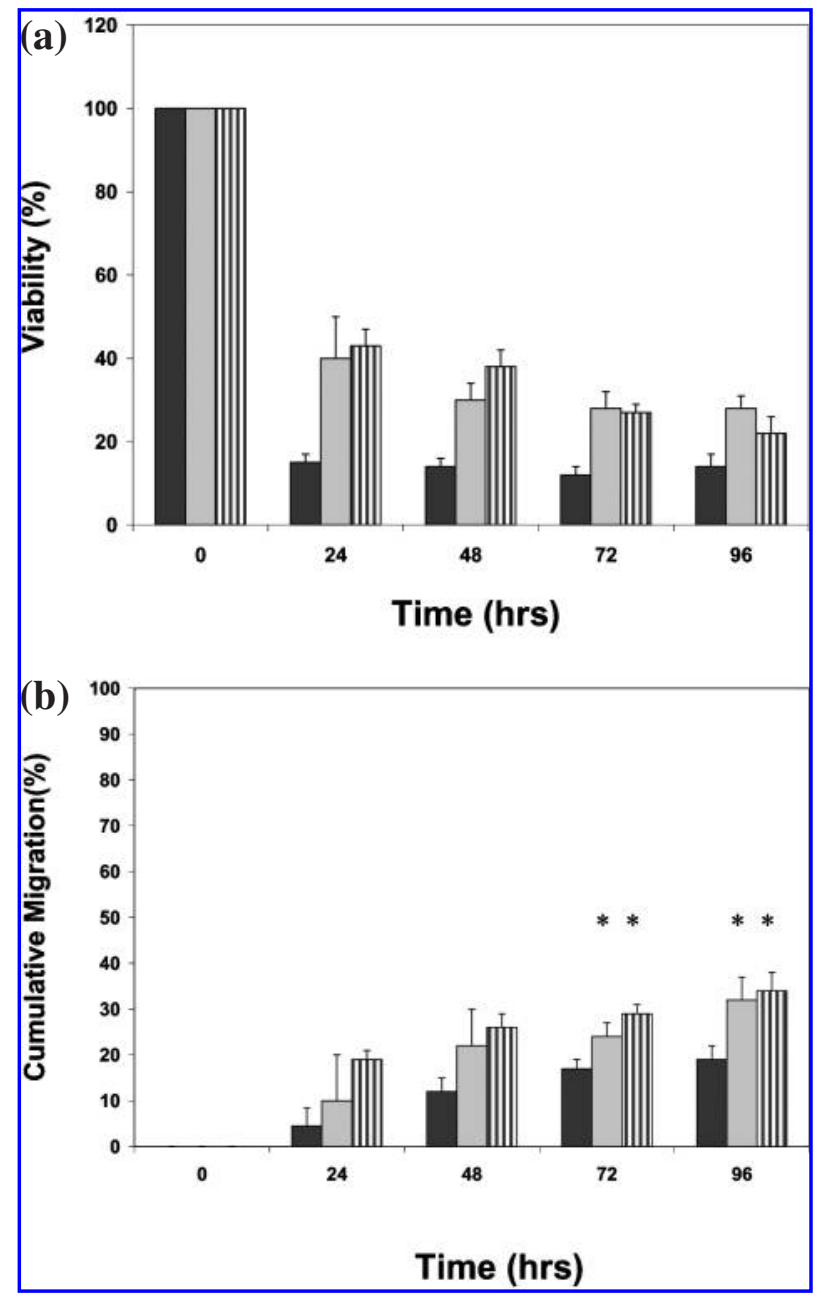

FIG. 3. Viability (a) and cumulative migration (b) are enhanced by peptide modification of alginate. Nanoporous alginate scaffolds (black bar), nanoporous scaffolds with HGFG release (gray bar), and microporous scaffolds with HGF release (striped bar). Numbers represent mean and SD $(n=8)$. *Statistically significant difference as compared to non-HGFG releasing scaffolds $(p<0.001)$. 
nuclear specific stain and immunohistochemical staining for desmin. Analysis via light microscopy of random microscopic fields revealed that the initial isolation yielded a heterogeneous population of cells, $75 \%$ of which expressed desmin (Fig. 1a). To enrich the cell culture for myogenic cells, initial primary cell isolates were expanded in culture for 7 days, and subsequently purified via Percoll density gradient fractionation. The resulting cultures consisted of a $95 \%$ desmin-positive population (Fig. 1b).

\section{Role of peptide modification}

The ability of myoblasts to both remain viable within and migrate from scaffolds without cell adhesion peptides was first tested by seeding myoblasts in scaffolds under the following three conditions: 1) nanoporous alginate scaffolds, 2) nanoporous scaffolds releasing HGF, and 3) microporous scaffolds releasing HGF. Approximately one third of incorporated HGF was released in the first $10 \mathrm{~h}$, and a sustained release was observed for the following time period (Fig. 2a) for all scaffold types. The percentage of cells that maintained viability over the first $24 \mathrm{~h}$ was $<10 \%$ under all conditions (Fig. 2b). By $96 \mathrm{~h}$, a small percentage of viable cells could only be measured in microporous scaffolds releasing HGF. Consistent with the cell loss was the minimal migration of myoblasts from the scaffolds (Fig. 2c). Over the first $24 \mathrm{~h},<5 \%$ of the total incorporated cells migrated from the scaffolds in any of these conditions. This increased slightly by day 2 in the microporous scaffolds, but failed to further improve in any condition.

Covalent modification of alginate with adhesion oligopeptides prior to scaffold fabrication improved both the viability of cells, as well as their outward migration (Fig. 3). Myoblasts seeded in nanoporous, peptide-modified scaffolds demonstrated a 2-fold increase in cell viability at $24 \mathrm{~h}$, as compared to cells in similar non-peptide modified scaffolds. HGF release further increased viability to $40 \%$, and cells seeded in peptide-modified microporous

(a)
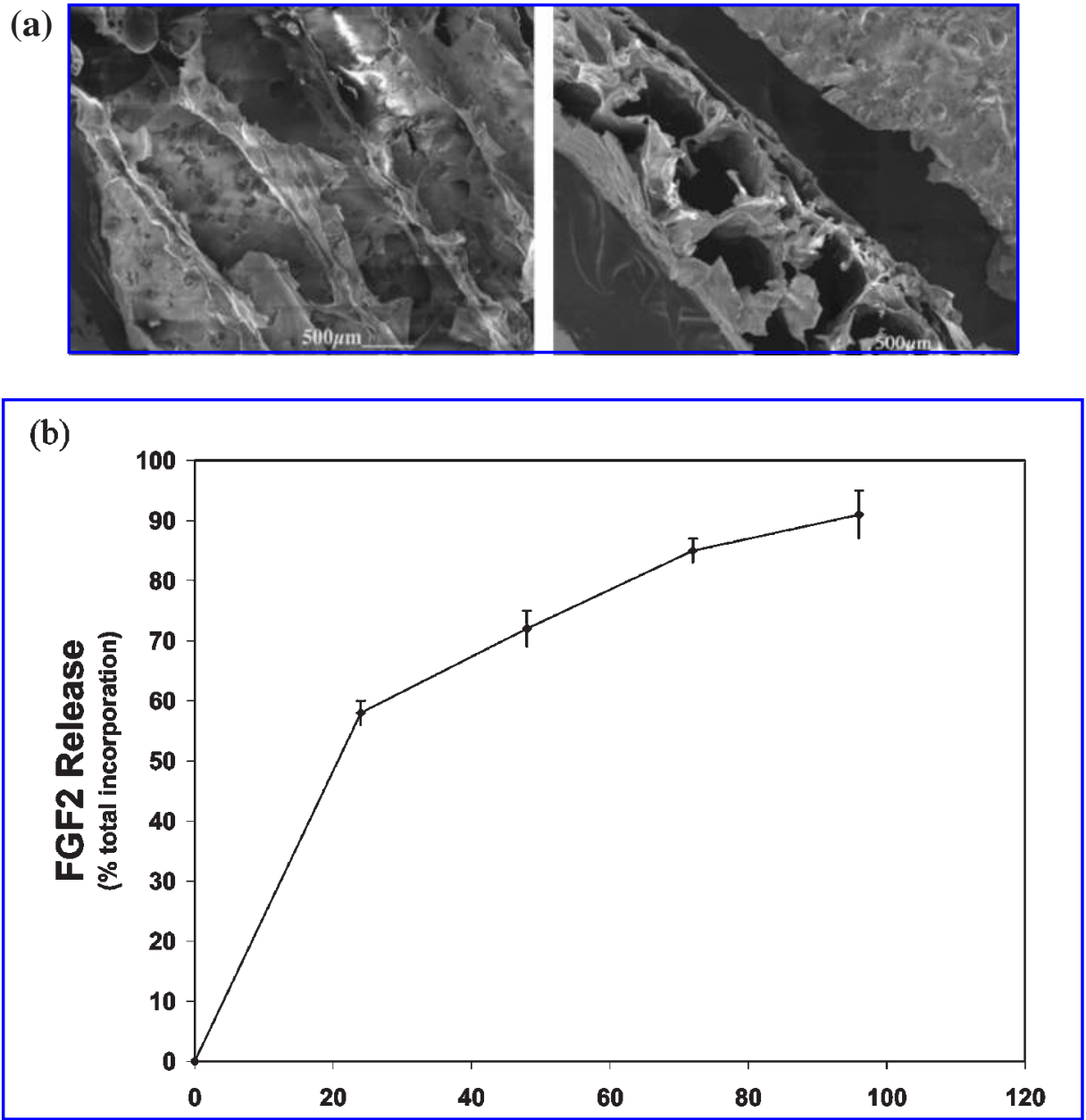

FIG. 4. SEM photomicrographs of side and end views of peptide-modified macroporous alginate (a) and release kinetics of FGF-2 (b). Values represent mean and SD $(n=4)$. 


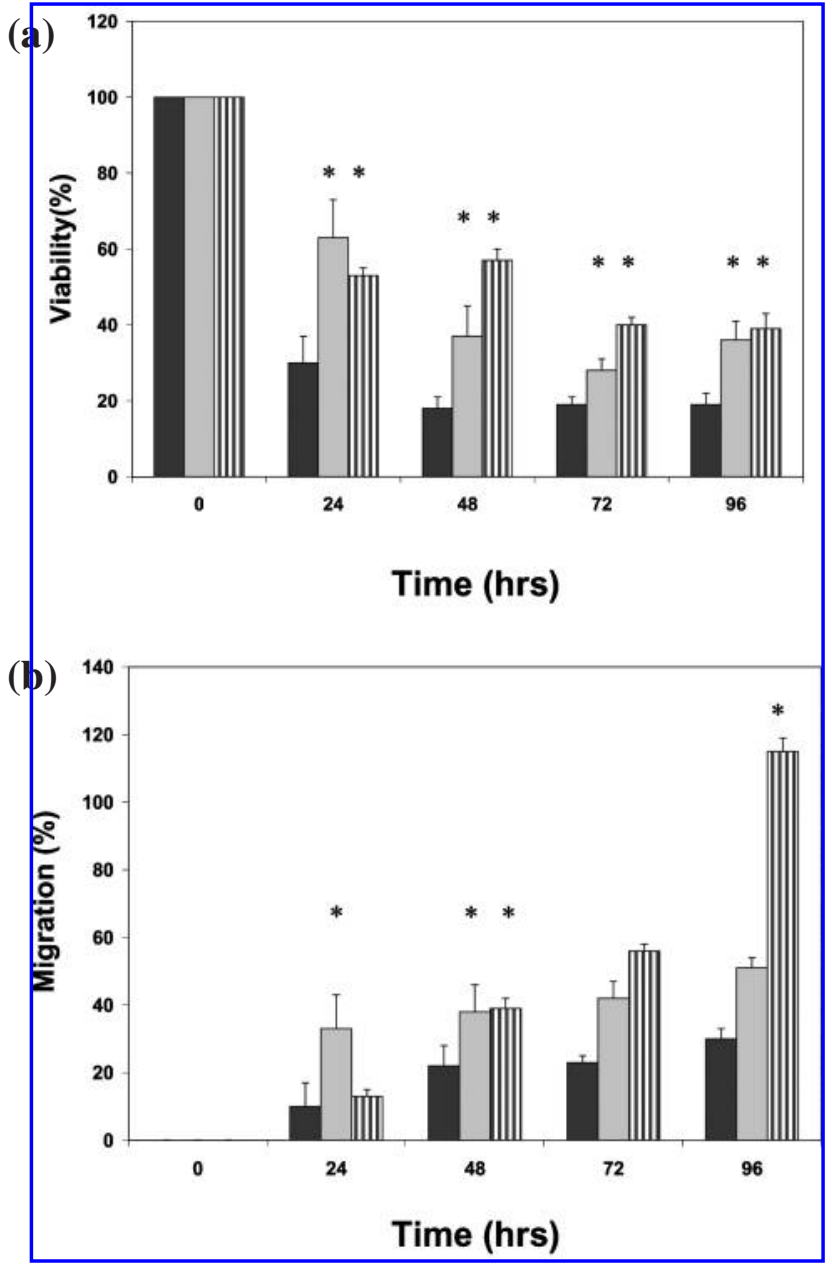

FIG. 5. Cell viability (a) and migration (b) is enhanced by macropores and FGF-2 release from peptide-modified alginate scaffolds. Macroporous alginate (black bar), macroporous alginate scaffolds releasing HGF (gray bar), and scaffolds releasing both HGF and FGF-2 (striped bar). Values represent mean values and $\mathrm{SD}(n=6)$. *Statistically significant differences $(p<0.01)$, as compared to non-HGF releasing conditions. scaffolds with HGF release demonstrated a similar viability (Fig. 3a). However, the viability decreased in all conditions over time. Similarly, cumulative migration was enhanced by peptide modification in concert with HGF release and microporosity. Peptide-modified nanoporous scaffolds led to approximately $20 \%$ of seeded cells migrating out of the scaffolds (Fig. 3b). Release of HGF by itself and in combination with micropores led to an approximately 4-fold increase in cell migration over non-peptide-modified nanoporous scaffolds (Fig. 3b). However, even under these conditions only $40 \%$ of the seeded cells migrated from the scaffolds, and thus would be available to fuse with host muscle fibers.

\section{Macroporous alginate and $F G F-2$ release}

The effects of creating aligned pore channels (macroporous scaffolds, Fig. 4a) and FGF-2 release (Fig. 4b) on the viability and outward migration of myoblasts seeded in peptide-modified scaffolds were examined next. Creation of macropores significantly enhanced both the viability and migration of myoblasts (Fig. 5), as compared to similar micro- or nanoporous scaffolds. Release of HGF further increased both survival and migration of myoblasts. The percentage of viable cells under this condition was $63 \%$ at $24 \mathrm{~h}$, and an enhanced viability was maintained through the $96 \mathrm{~h}$ of the experiment (Fig. 5a). Furthermore, release of HGF and FGF-2 together led to the greatest level of outward migration (Fig. 5b). Specifically, while one million cells were initially seeded into these scaffolds, there were $3.8 \times 10^{5}$ viable cells within the scaffolds at 4 days and $1.06 \times 10^{6}$ cells had migrated out of the scaffolds by this time.

Western blot analysis of cell lysates was performed to determine the differentiation state of cells within and migrating from these scaffolds. Cells present in or migrating from scaffolds releasing HGF and FGF-2 expressed high levels of MyoD (Fig. 6). Cells present in scaffolds

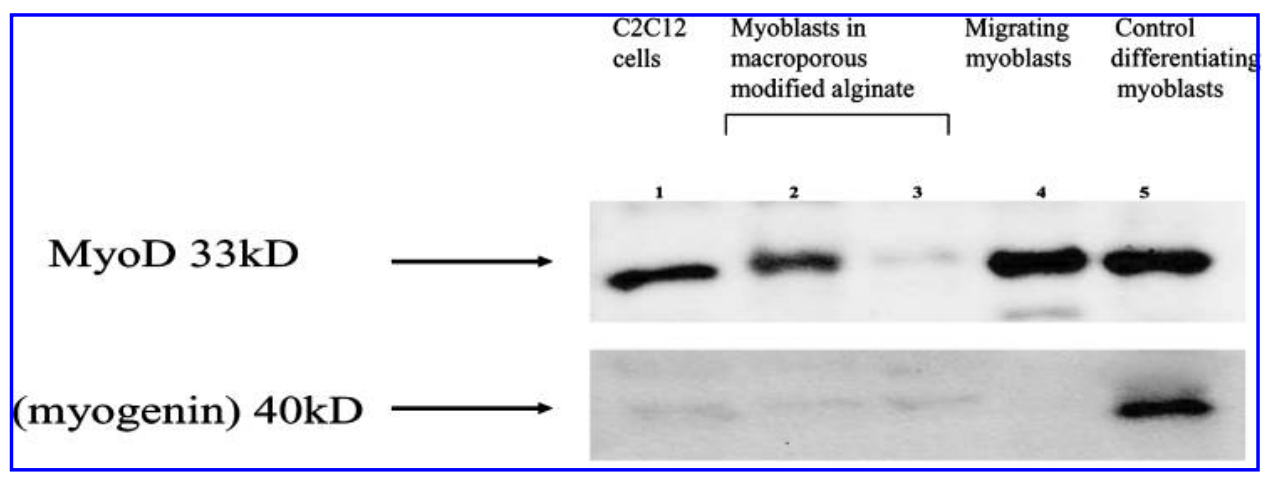

FIG. 6. Western blot analysis of cell lysates from myoblasts cultured in macroporous scaffolds fabricated from peptide-modified alginate either with $(+)$ (lane 2) or without $(-)$ (lane 3) release of HGF and FGF-2. Cells migrating from scaffolds were also analyzed (lane 4). Controls of lysates from C2C12 cell line (lane 1), and primary myoblasts cultured in standard two-dimensional conditions that promote differentiation (lane 5) are also shown. 
without peptide modification or HGF/FGF-2 did not express significant levels of MyoD. In contrast, neither cells within the scaffolds nor those that migrated from the scaffolds expressed myogenin, a transcription factor associated with end-stage differentiation of myogenic cells (Fig. 6).

\section{DISCUSSION}

The viability and ability of myoblasts to migrate from vehicles potentially useful for their transplantation were found to be strongly regulated by the presentation of cell adhesion ligands by the material, pore structure, and release of growth factors from the material.

Incorporation of myoblasts into scaffolds lacking cell adhesion ligands led to rapid and severe loss of viability, and cell migration was minimal. However, modification of alginate with a $\mathrm{G}_{4} \mathrm{RGDSP}$ peptide increased cell viability and migration. Several previous studies have demonstrated that alginate modified with a similar cell adhesion peptide ${ }^{36-39}$ allowed cells to adhere to this polymer, proliferate, and in the case of myoblasts, fuse into myofibrils. ${ }^{40}$ In concert with the recently demonstrated importance of coupled peptides to tissue formation by transplanted cells, ${ }^{32,41}$ these findings suggest a key role for this variable in scaffold design for muscle tissue engineering. Peptides that present motifs found in fibronectin (e.g., RGD) may be especially relevant to the goals of the approach to skeletal muscle engineering pursued in the current work, as myoblast adhesion to fibronectin is associated with the early proliferative phase of myogenesis. ${ }^{42}$ However, in this study the RGD signal alone gave inadequate signals for robust migration of myoblasts out of the scaffolds. Aligned macropores in the scaffolds led to a higher cell survival at later time points and, most importantly, a very efficient migration of cells out of the scaffolds. Macroporous alginate scaffolds have previously been demonstrated to allow for the migration of cells into alginate scaffolds in vivo. ${ }^{43} \mathrm{Sim}-$ ilarly, smooth muscle cells have been demonstrated to grow most favorably on scaffolds with larger pores. ${ }^{44}$

Incorporation of two growth factors known to influence myoblast phenotype significantly increased the viability and migration of seeded myoblasts under all variations of scaffold chemistry and architecture tested in these studies. FGFs were the first growth factors shown to have an effect on myogenic cells, ${ }^{45}$ and more recent studies describe that the FGF-2 effect on myogenic cells is enhanced by the addition of HGF. ${ }^{46}$ In addition, myogenic repair in a muscle crush injury was hindered by the injection of FGF-2 antibodies. ${ }^{47}$ Taken together, these studies support both an important physiological role for FGF-2 and a role for combined FGF-2 and HGF signaling in skeletal muscle regeneration. However, injection of FGF-2 into skeletal muscle after injury did not enhance muscle repair, ${ }^{48}$ suggesting the importance of using this factor in the proper context. In particular, in the current approach to regenerate skeletal muscle, myogenic cells must be directed to bypass their normal tendency to differentiate and remain in a proliferative phase until a sufficient number of cells is attained to regenerate the tissue and the cells have also migrated from the scaffold. Based on the results of this current study, FGF-2 may be particularly useful in promoting the proliferation of cells in the scaffolds while preventing their premature differentiation, while the migration-inducing effects of HGF provide the latter function.

These results have clear implications for skeletal muscle tissue engineering, as they demonstrate that vehicles for primary myoblast delivery can be designed to maintain cell viability and promote migration out of the vehicle. Appropriate combinations of scaffold architecture, adhesion ligands that maintain viability and allow migration, and growth factors that regulate phenotype can be used in combination to obtain complex control over the fate of the transplanted cells.

\section{ACKNOWLEDGMENT}

This work was supported by the NIH/NICDR (RO1 DE13349).

\section{REFERENCES}

1. WHO. Global burden of musculoskeletal disease revealed in new WHO report. Bull. World Health Org. 81, 853, 2003.

2. Rappolee, D.A., and Werb, Z. Macrophage-derived growth factors. Curr.Top. Microbiol. Immunol. 181, 87, 1992.

3. Straub, V., Rafael, J.A., Chamberlain, J.S., and Campbell, K.P. Animal models for muscular dystrophy show different patterns of sarcolemmal disruption. J. Cell Biol. 139, 375, 1997.

4. Tidball, J.G. Inflammatory cell response to acute muscle injury. Med. Sci. Sports Exerc. 27, 1022, 1995.

5. Hill, M., Wernig, A., and Goldspink, G. Muscle satellite (stem) cell activation during local tissue injury and repair. J. Anat. 203, 89, 2003.

6. Johnson, S.E., and Allen, R.E. Activation of skeletal muscle satellite cells and the role of fibroblast growth factor receptors. Exp. Cell Res. 219, 449, 1995.

7. Miller, K.J., Thaloor, D., Matteson, S., and Pavlath. G.K. Hepatocyte growth factor affects satellite cell activation and differentiation in regenerating skeletal muscle. Am. J. Physiol. Cell Physiol. 278, C174, 2000.

8. Seale, P., Sabourin, L.A., Girgis-Gabardo, A., Mansouri, A., Gruss, P., and Rudnicki, M.A. Pax7 is required for the specification of myogenic satellite cells. Cell 102, 777, 2000 . 
9. Horsley, V., Jansen, K.M., Mills, S.T., and Pavlath, G.K. IL-4 acts as a myoblast recruitment factor during mammalian muscle growth. Cell 113, 483, 2003.

10. Zammit, P.S., Heslop, L., Hudon, V., Rosenblatt, J.D., Tajbakhsh, S., Buckingham, M.E., Beauchamp, J.R., and Partridge, T.A. Kinetics of myoblast proliferation show that resident satellite cells are competent to fully regenerate skeletal muscle fibers. Exp. Cell Res. 281, 39, 2002.

11. Hanada, E.Y. Efficacy of rehabilitative therapy in regional musculoskeletal conditions. Best Pract. Res. Clin. Rheumatol. 17, 151, 2003.

12. Conboy, I.M., and Rando, T.A. The regulation of Notch signaling controls satellite cell activation and cell fate determination in postnatal myogenesis. Dev. Cell 3, 397, 2002.

13. Zammit, P.S., Golding, J.P., Nagata, Y., Hudon, V., Partridge, T.A., and Beauchamp, J.R. Muscle satellite cells adopt divergent fates: a mechanism for self-renewal? J. Cell Biol. 166, 347, 2004.

14. Leshem, Y., Spicer, D.B., Gal-Levi, R., and Halevy, O. Hepatocyte growth factor (HGF) inhibits skeletal muscle cell differentiation: a role for the bHLH protein twist and the cdk inhibitor p27. J. Cell Physiol. 184, 101, 2000.

15. Rubin, J.S., Day, R.M., Breckenridge, D., Atabey, N., Taylor, W.G., Stahl, S.J., Wingfield, P.T., Kaufman, J.D., Schwall, R., and Bottaro, D.P. Dissociation of heparan sulfate and receptor binding domains of hepatocyte growth factor reveals that heparan sulfate-c-met interaction facilitates signaling. J. Biol. Chem. 276, 32977, 2001.

16. Tatsumi, R., Anderson, J.E., Nevoret, C.J., Halevy, O., and Allen, R.E. HGF/SF is present in normal adult skeletal muscle and is capable of activating satellite cells. Dev. Biol. 194, 114, 1998.

17. Allen, R.E., Dodson, M.V., and Luiten, L.S. Regulation of skeletal muscle satellite cell proliferation by bovine pituitary fibroblast growth factor. Exp. Cell Res. 152, 154, 1984.

18. Cornelison, D.D., and Wold, B.J. Single-cell analysis of regulatory gene expression in quiescent and activated mouse skeletal muscle satellite cells. Dev. Biol. 191, 270, 1997.

19. Cornelison, D.D., Filla, M.S., Stanley, H.M., Rapraeger, A.C., and Olwin, B.B. Syndecan-3 and syndecan-4 specifically mark skeletal muscle satellite cells and are implicated in satellite cell maintenance and muscle regeneration. Dev. Biol. 239, 79, 2001.

20. Rapraeger, A.C. Syndecan-regulated receptor signaling. J. Cell Biol. 149, 995, 2000.

21. Pelinkovic, D., Martinek, V., Engelhardt, M., Lee, J.Y., Fu, F., and Huard, J. [Tissue engineering and gene therapy of the musculoskeletal system with muscle cells.] Z. Orthop. Ihre Grenzgeb. 138, 402, 2000.

22. Wright, V.J., Peng, H., and Huard, J. Muscle-based gene therapy and tissue engineering for the musculoskeletal system. Drug Discov. Today 6, 728, 2001.

23. Heslop, L., Beauchamp, J.R., Tajbakhsh, S., Buckingham, M.E., Partridge, T.A., and Zammit, P.S. Transplanted primary neonatal myoblasts can give rise to functional satellite cells as identified using the Myf5nlacZl+ mouse. Gene Ther. 8, 778, 2001.
24. Gussoni, E., Soneoka, Y., Strickland, C.D., Buzney, E.A., Khan, M.K., Flint, A.F., Kunkel, L.M., and Mulligan, R.C. Dystrophin expression in the mdx mouse restored by stem cell transplantation. Nature 401, 390, 1999.

25. Saxena, A.K., Marler, J., Benvenuto, M., Willital, G.H., and Vacanti, J.P. Skeletal muscle tissue engineering using isolated myoblasts on synthetic biodegradable polymers: preliminary studies. Tissue Eng. 5, 525, 1999.

26. Skuk, D., Goulet, M. Roy, B., and Tremblay. J.P. Efficacy of myoblast transplantation in nonhuman primates following simple intramuscular cell injections: toward defining strategies applicable to humans. Exp. Neurol. 175, 112, 2002.

27. Pouzet, B., Vilquin, J.T., Hagege, A.A., Scorsin, M., Messas, E., Fiszman, M., Schwartz, K., and Menasche, P. Factors affecting functional outcome after autologous skeletal myoblast transplantation. Ann. Thorac. Surg. 71, 844; discussion 850, 2001.

28. Skuk, D., and Tremblay, J.P. Myoblast transplantation: the current status of a potential therapeutic tool for myopathies. J. Muscle Res. Cell Motil. 24, 285, 2003.

29. Wernig, A., Zweyer, M., and Irintchev, A. Function of skeletal muscle tissue formed after myoblast transplantation into irradiated mouse muscles. J. Physiol. 522 Pt 2, 333, 2000.

30. Beauchamp, J.R., Morgan, J.E., Pagel, C.N., and Partridge, T.A. Dynamics of myoblast transplantation reveal a discrete minority of precursors with stem cell-like properties as the myogenic source. J. Cell Biol. 144, 1113, 1999.

31. Qu, Z., Balkir, L., van Deutekom, J.C., Robbins, P.D., Pruchnic, R., and Huard, J. Development of approaches to improve cell survival in myoblast transfer therapy. J. Cell Biol. 142, 1257, 1998.

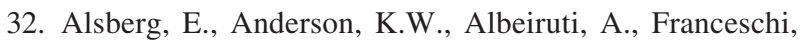
R.T., and Mooney, D.J. Cell-interactive alginate hydrogels for bone tissue engineering. J. Dent. Res. 80, 2025, 2001.

33. Li, A.A., MacDonald, N.C., and Chang, P.L. Effect of growth factors and extracellular matrix materials on the proliferation and differentiation of microencapsulated myoblasts. J. Biomater. Sci. Polym. Ed. 14, 533, 2003.

34. Rowley, J.A., Madlambayan, G., and Mooney, D.J. Alginate hydrogels as synthetic extracellular matrix materials. Biomaterials 20, 45, 1999.

35. Kong, H.J., Kaigler, D., Kim, K., and Mooney, D.J. Controlling rigidity and degradation of alginate hydrogels via molecular weight distribution. Biomacromolecules 5, 1720, 2004.

36. Kong, H.J., Smith, M.K., and Mooney, D.J. Designing alginate hydrogels to maintain viability of immobilized cells. Biomaterials 24, 4023, 2003.

37. Rowley, J. Alginate type and RGD density control myoblast phenotype. J. Biomed. Mater. Res. 60, 217, 2002.

38. Chan, C., Burrows, L.L., and Deber, C.M. Helix induction in antimicrobial peptides by alginate in biofilms. J. Biol. Chem. 279, 38749, 2004.

39. Hashimoto, T., Suzuki, Y., Tanihara, M., Kakimaru, Y., and Suzuki, K. Development of alginate wound dressings linked with hybrid peptides derived from laminin and elastin. Biomaterials 25, 1407, 2004. 
40. Rowley, J.A., Madlambayan, G., and Mooney, D.J. Alginate hydrogels as synthetic extracellular matrix materials. Biomaterials 20, 45, 1999.

41. Alsberg, E., Anderson, K.W., Albeiruti, A., Rowley, J.A., and Mooney, D.J. Engineering growing tissues. Proc. Natl. Acad. Sci. USA 99, 12025, 2002.

42. Gullberg, D., and Ekblom, P. Extracellular matrix and its receptors during development. Int. J. Dev. Biol. 39, 845, 1995.

43. Eiselt, P., Yeh, J., Latvala, R.K., Shea, L.D., and Mooney, D.J. Porous carriers for biomedical applications based on alginate hydrogels. Biomaterials 21, 1921, 2000.

44. Zeltinger, J., Sherwood, J.K., Graham, D.A., Mueller, R., and Griffith, L.G. Effect of pore size and void fraction on cellular adhesion, proliferation, and matrix deposition. Tissue Eng. 7, 557, 2001.

45. Gospodarowicz, D., Weseman, J., Moran, J.S., and Lindstrom, J. Effect of fibroblast growth factor on the division and fusion of bovine myoblasts. J. Cell Biol. 70, 395, 1976.

46. Sheehan, S.M., and Allen, R.E. Skeletal muscle satellite cell proliferation in response to members of the fibroblast growth factor family and hepatocyte growth factor. J. Cell Physiol. 181, 499, 1999.

47. Lefaucheur, J.P., and Sebille, A. The cellular events of injured muscle regeneration depend on the nature of the injury. Neuromusc. Disord. 5, 501, 1995.

48. Mitchell, C.A., McGeachie, J.K., and Grounds, M.D. The exogenous administration of basic fibroblast growth factor to regenerating skeletal muscle in mice does not enhance the process of regeneration. Growth Factors 13, 37, 1996.

Address reprint requests to: David Mooney Division of Engineering and Applied Sciences 29 Oxford St., 319 Pierce Hall Harvard University Cambridge, MA 02139

E-mail: mooneyd@deas.harvard.edu 


\section{This article has been cited by:}

1. Hideaki Fujita, Kazunori Shimizu, Eiji Nagamori. 2009. Novel method for fabrication of skeletal muscle construct from the C2C12 myoblast cell line using serum-free medium AIM-V. Biotechnology and Bioengineering 103:5, 1034-1041. [CrossRef]

2. Gianni Albertini , Alessandra Giuliani , Vladimir Komlev, Francesca Moroncini , Armanda Pugnaloni , Giuseppina Pennesi , Marzia Belicchi , Corrado Rubini , Franco Rustichelli , Roberta Tasso , Yvan Torrente . Organization of Extracellular Matrix Fibers Within Polyglycolic Acid-Polylactic Acid Scaffolds Analyzed Using X-Ray Synchrotron-Radiation Phase-Contrast Micro Computed TomographyOrganization of Extracellular Matrix Fibers Within Polyglycolic Acid-Polylactic Acid Scaffolds Analyzed Using X-Ray Synchrotron-Radiation Phase-Contrast Micro Computed Tomography. Tissue Engineering Part C: Methods, ahead of print. [Abstract] [PDF] [PDF Plus]

3. J. J. Gavira, G. Abizanda, M. Perez-Ilzarbe, D. Martinez-Caro, E. Nasarre, A. Perez-Ruiz, F. Prosper. 2009. Skeletal myoblasts for cardiac repair in animal models. European Heart Journal Supplements 10:Suppl K, K11-K15. [CrossRef]

4. Catherine K. Kuo, Peter X. Ma. 2008. Maintaining dimensions and mechanical properties of ionically crosslinked alginate hydrogel scaffoldsin vitro. Journal of Biomedical Materials Research Part A 84A:4, 899-907. [CrossRef]

5. Jonathan H. Dinsmore, Nabil Dib. 2008. Stem Cells and Cardiac Repair: A Critical Analysis. Journal of Cardiovascular Translational Research 1:1, 41-54. [CrossRef]

6. Miguel Cortes-Morichetti, Giacomo Frati , Olivier Schussler, Jean-Paul Duong Van Huyen, Evelyne Lauret , Jorge A. Genovese , Alain F. Carpentier, Juan C. Chachques . 2007. Association Between a Cell-Seeded Collagen Matrix and Cellular Cardiomyoplasty for Myocardial Support and RegenerationAssociation Between a Cell-Seeded Collagen Matrix and Cellular Cardiomyoplasty for Myocardial Support and Regeneration. Tissue Engineering 13:11, 2681-2687. [Abstract] [PDF] [PDF Plus]

7. Luisa Boldrin, Jennifer E Morgan. 2007. Activating muscle stem cells: therapeutic potential in muscle diseases. Current Opinion in Neurology 20:5, 577-582. [CrossRef]

8. Sander Grefte , Anne Marie Kuijpers-Jagtman, Ruurd Torensma , Johannes W. Von den Hoff . 2007. Skeletal Muscle Development and RegenerationSkeletal Muscle Development and Regeneration. Stem Cells and Development 16:5, 857-868. [Abstract] [PDF] [PDF Plus]

9. Biancamaria Baroli. 2007. Hydrogels for tissue engineering and delivery of tissue-inducing substances. Journal of Pharmaceutical Sciences 96:9, 2197-2223. [CrossRef]

10. Tanyarut Boontheekul, Elliott E. Hill , Hyun-Joon Kong, David J. Mooney . 2007. Regulating Myoblast Phenotype Through Controlled Gel Stiffness and DegradationRegulating Myoblast Phenotype Through Controlled Gel Stiffness and Degradation. Tissue Engineering 13:7, 1431-1442. [Abstract] [PDF] [PDF Plus]

11. David S. Hart, Stevin H. Gehrke. 2007. Thermally associating polypeptides designed for drug delivery produced by genetically engineered cells. Journal of Pharmaceutical Sciences 96:3, 484-516. [CrossRef] 